\title{
FATORES DE PRESSÃO NO TRABALHO DE CONTADORES QUE ATUAM EM ESCRITÓRIOS DE CONTABILIDADE NA CIDADE DE BELO HORIZONTE - MG.
}

\author{
Ramon Silva Peres ${ }^{1}$, Larissa Rodrigues Rocha de Medeiros ${ }^{2}$, Luciara Bernardo \\ Bernardo $^{3}$, Aline Ellen Torres dos Santos ${ }^{4}$, Luana Cristina Cristina ${ }^{5}$, Alexandre Junio \\ Ferreira Silva $^{6}$
}

\section{RESUMO}

Pesquisa descritiva que tem como objetivo conhecer as principais causas que pressionam o contador no exercício de sua profissão. Entrevistas com cinco profissionais de contabilidade, sendo três do sexo feminino e dois do sexo masculino. Os dados foram coletados em setembro de 2014, sendo transcritos e analisadas. As principais causas que levam os contadores ao estresse são o volume excessivo de atividades a serem entregues dentro do prazo exigido, ritmo acelerado, extensa jornada de trabalho, entre outras causas. Eles manifestaram ter apresentado, no decorrer de suas atividades, diversos sinais e sintomas físicos de estresse, como dores nos ombros e nos braços. Para redução do estresse os entrevistados realizam atividades com os amigos, consomem bebidas alcoólicas, etc. Conclui-se que se faz necessária a adoção de medidas de combate ao estresse, tanto organizacionais quanto dos profissionais estudados.

Palavras-chave: Estresse ocupacional. Contadores. Pressão no trabalho.

\section{PRESSURE FACTORS AT WORK COUNTERS WORKING IN ACCOUNTING FIRMS IN THE CITY OF BELO HORIZONTE - MG.}

\begin{abstract}
Descriptive research that aims to know the main causes pressing the counter in the exercise of their profession. Interviews with five accounting professionals, three female and two male. Data were collected in September 2014, being transcribed and analyzed. The main causes that lead accountants to stress are excessive volume of activities to be delivered within the required time frame, fast-paced, long working hours, among other causes. They reported having presented in the course of their activities, many physical signs and symptoms of stress, such as pain in the shoulders and arms. For stress reduction respondents carry out activities with friends, drink alcohol, etc. It concludes that is necessary to adopt anti-stress measures, both organizational as the studied professionals.
\end{abstract}

Keywords: Occupational stress. Counters. Pressure at work.

\section{INTRODUÇÃO}

O estresse é o resultado de uma relação entre o indivíduo e o ambiente em que vive. De acordo com Zanelli (2010), o estresse é amplamente compreendido como uma necessidade

\footnotetext{
${ }^{1}$ Centro Universitário Newton Paiva

${ }^{2}$ Centro universitário Newton Paiva

${ }^{3}$ Centro universitário Newton Paiva

${ }^{4}$ Centro universitário Newton Paiva

${ }^{5}$ Centro universitário Newton Paiva

${ }^{6}$ Centro universitário Newton Paiva
} 
de adaptação ou ajustamento de um organismo frente às pressões que o ambiente impõe. Suas consequências sobre a saúde do indivíduo constituem objetos de estudos na esfera mundial, tornando-se uma fonte importante de preocupação no meio organizacional. Na visão de Goldberg (1986), as situações de tensão excessiva no trabalho vêm contribuindo para provocar nos indivíduos importantes quadros de estresse.

Para Cooper, Sloan e Willians (1998), a partir do Modelo Dinâmico do Estresse Organizacional, os agentes estressores, potencialmente causadores de estresse, estão presentes em todos os ambientes de trabalho e relações interpessoais, sendo estes representados por elementos intra e extra organização. Nesse ínterim, torna-se fundamental elucidar as diferentes dimensões que envolvem a gênese do estresse, considerando, principalmente, o binômio trabalhador e organização em tal fenômeno.

Nos últimos tempos os profissionais estão submetidos às grandes pressões, gerados pela competitividade em busca de resultados, elevadas exigências, complexidade das atividades a serem desenvolvidas em menores quantidades de tempo. A indefinição e a competição são igualmente acirradas no mundo atual, o que provoca ansiedade e modificações no comportamento das pessoas. Esses aspectos aparecem também nas organizações, que passam por profundas mudanças diante desse contexto altamente competitivo. Elas buscam uma nova forma de atuar, por meio da modificação de seu sistema de gestão ou do ambiente no qual está inserida. (MOLINA, 1996).

Uma pesquisa realizada pela International Stress Management Association (ISMABR) concluiu que cerca de $70 \%$ dos brasileiros sofrem de estresse no trabalho. Mesmo estudo revelou que $30 \%$ apresentam sintomas da síndrome de burnout, ou seja, estão em um estado de exaustão adiantado, à beira de um quadro de depressão (BENEDICTO, 2006).

Dentre os principais motivos do estresse estão às mudanças constantes que ocorrem na sociedade moderna. De acordo com as mudanças em virtude da adoção dos padrões contábeis Internacionais de Contabilidade do IASB, Lei n. 6.404, de 1976, mudanças essas que ocorrem de maneira rápida, impedindo que os indivíduos possam absorvê-las de forma correta. Devese estar sempre atento, pois a difusão do conhecimento torna um profissional extremamente qualificado em ultrapassado em questão de dias. O estresse pode fazer com que o contabilista cometa erros que posam vir a gerar multas. As mudanças em virtude da adoção dos padrões contábeis Internacionais de Contabilidade do IASB, Lei n. 6.404, de 1976. Portanto, caso um indivíduo esteja com estresse, ele pode perder desempenho e cometer erros, prejudicando a instituição na qual trabalha. 
Nesse contexto nosso estudo tem a intenção de identificar: Como estão configuradas as variáveis de pressão no trabalho dos contadores que atuam em escritórios de contabilidade na região de Belo Horizonte - MG?

Analisar e descrever os fatores potenciais de estresse ocupacional que estão presentes no trabalho dos contadores que atuam em escritórios de contabilidade na região de Belo Horizonte - MG, descrever os sintomas físicos e mentais decorrentes dessa pressão e as estratégias de combate ao estresse utilizadas pelos sujeitos da pesquisa.

\section{REFERENCIAL TEÓRICO}

Este referencial teórico está estruturado em quatro tópicos. No primeiro, discutem-se o conceito e as características do estresse, segundo, identificam-se o estresse ocupacional, e as estratégias de enfrentamento ao estresse; no terceiro, apresenta-se o modelo de Cooper, Sloan e William para o diagnóstico de estresse ocupacional, e no quarto, A função do contador e suas responsabilidades na atualidade e o estresse ocupacional.

\subsection{Estresse: Conceitos e características}

É quase que impossível, em jornais, revistas ou na televisão não ouvir falar a palavra estresse. De acordo com Rosch (2001) esse tema vem sendo estudado e comentado dia a dia e nas últimas décadas os níveis de estresse aumentaram significativamente, e no caso dos adultos a maior fonte do estresse e o estresse ocupacional.

Goldberg (1980) Aponta que o estresse envolvendo fatores fisiológicos, afirmando assim que, é um estado que manifesta uma síndrome específica de fatos biológicos. Como são geradas modificações no sistema biológico, com uma variedade de agentes, entende-se que o estresse é introduzido. Assim sendo, o autor afirma que estresse é uma sobrecarga dos recursos do corpo, com a finalidade de responder alguma situação ambiental.

O estresse gera preocupação, ainda segundo Goldberg (1980), uma vez que pode levar ao surgimento de ansiedade, doenças cardiovasculares, impotência infertilidade, depressão, dentre outros quadros clínicos, simples ou graves.

Selye (1956) confirma que o fenômeno, é entendido considerando sua duração, pressionadores ou não, o equilíbrio do individuo com relação aos estímulos e as exigências exercidas pelo meio ambientes quanto à adaptação individual. Diz ainda, que quanto à 
duração, o estresse pode ser agudo se decorrer de reações individuais imediatas a pressões e crônico quando as reações estressantes durarem mais tempo. As formas positivas e equilibradas e as negativas e descompensadoras, podem motivar ou debilitar o uso de energias do indivíduo quanto à relação mantida com o ambiente. $\mathrm{O}$ autor apresenta ainda que o estresse como uma síndrome de adaptação que afeta as reações do corpo em meio a agentes externos. O autor dá ênfase à dimensão biológica do estresse, excluindo a especificidade das reações fisiológicas que são dependentes da interpretação dada pelo indivíduo ao evento estressante, bem como da sua forma de enfrentamento.

De acordo com Zille (2005) existem abordagens teóricas complementares e interligadas sobre o estresse, a biológica que tem foco na fisiologia do estresse, a psicológica que busca entender como a percepção e o comportamento do individuo são manifestados enquanto o estresse se forma e a sociológica que está ligada a sociedade e o psíquico do individuo.

\subsection{Estresse ocupacional}

O estresse ocupacional, ou profissional, configura-se quando a origem dos agentes estressores é eminentemente proveniente do espaço de trabalho ou decorrente das atividades realizadas naquele ambiente (MARRAS; VELOSO, 2012).

França e Rodrigues (1999) dizem que as condições de trabalho geram fatores estressantes, quando não há uma boa relação entre os funcionários, o que gera um ambiente hostil entres as pessoas, sem cooperação, competição, discussões inúteis e trabalho isolado. Os autores acrescentam também, que a dificuldade de o indivíduo se adaptar a um meio dinâmico envolve seus interesses pessoais e seu psicológico.

Nem todo estimulo externo ou interno ao individuo, é suficientemente potente para ser tratado como pressão, alterar o equilíbrio do organismo e levar a uma resposta de estresse, de acordo com Lipp (2004) sendo evidenciado algum desequilíbrio, sempre ocorrerá uma resposta do organismo no sentido de reestabelecer seu percurso natural de energia.

De acordo com Tamayo (2008) o que é vivenciado no dia a dia das organizações, como situações ameaçadoras, fortes cargas de pressão, segurança, autoestima, condições de trabalho e convívio, são o que leva às constantes expressões de tensão. $\mathrm{O}$ autor afirma ainda, que as tentativas de acabar com o estresse têm desencadeado diversos tipos de problemas, como uso excessivo de álcool, drogas, falta de comprometimento, afastamento do trabalho, 
insatisfação e baixa produtividade. Logo o autor também destaca, que exigências do trabalho, tarefas excessivas, redução de funcionários, a necessidade de manter-se na empresa e o rompimento das relações com e no trabalho são contribuintes para o estresse nas organizações.

Fraser (1983) afirma que o estresse ocupacional trata-se de uma reação do indivíduo ao seu ambiente de trabalho, que, de alguma forma, o atinge. Essas ameaças podem ser entendidas como agentes estressores que caracterizam uma relação pouco produtiva entre a estrutura do indivíduo e seu ambiente de trabalho, demonstrando que excessivas mudanças estão sendo direcionadas ao trabalhador e que ele não está devidamente preparado, do ponto de vista psicológico, para internalizá-las de forma positiva.

\subsection{O modelo de Cooper, Sloan e Williams para o diagnóstico de estresse ocupacional.}

Na concepção de Cooper, Sloan e Williams (1988), todo trabalho tem a presença de fatores causadores de estresse, o que muda são os tipos de fatores causadores e a intensidade com que se manifestam e que estão condicionados a particularidades das organizações e dos indivíduos.

O modelo de Cooper, Sloan e Williams (1988), muito bem conceituado em diversos estudos quanto ao assunto, é um modelo teórico que apresenta os causadores da pressão no trabalho e as consequências desses causadores no ambiente organizacional e nos indivíduos. Neste modelo os autores estabelecem seis fatores ou categorias de pressão que podem ser fonte de estresse ocupacional, sendo: fatores intrínsecos ao trabalho; papel gerencial; interrelacionamento; desenvolvimento na carreira; clima e estrutura organizacional; e interface casa e trabalho. Onde os fatores intrínsecos ao trabalho são ligados a natureza e conteúdo do trabalho exercido. O papel gerencial diz respeito a controle sobre o trabalho. $\mathrm{O}$ interrelacionamento refere-se a convivência das pessoas dentro e também fora do trabalho. $\mathrm{O}$ fator de desenvolvimento na carreira está ligado às possíveis oportunidades que a organização fornece como compensação, promoção ou valorização. A estrutura e clima referem-se a atividades internas organizacionais para que o ambiente mantenha-se agradável. E por último, o fator interface casa/trabalho que diz respeito à conciliação da vida profissional com a vida pessoal. 
Fraser (1983) ressalta que o ambiente de trabalho é interativo e que o estresse ocupacional estaria presente, nesse contexto, ao longo dos componentes deste macrossistema produtivo. Segundo o autor, elementos específicos, como calor, barulho, e uma série de condições físicas e psicossociais intoleráveis funcionam como estímulos com potencialidade para provocar estresse nos trabalhadores, gerando maior ou menor insatisfação da força de trabalho em relação a suas atividades, bem como efeitos diversos em seu desempenho e produtividade.

Humphrey e Humphrey (1986) intitulam as fontes de tensão como "estímulos nocivos" e esclarecem que cada indivíduo reage a eles de forma diferente, de acordo com suas características individuais, ligadas ao gênero e à personalidade.

Reiterando as visões das fontes de tensão no trabalho segundo as diferentes perspectivas, vê-se que na abordagem biológica elas são vistas como os estímulos físicos ou psicológicos que vão desencadear o processo de estresse ocupacional, em uma relação de causa e efeito. Segundo Marras e Veloso (2012), é como se as fontes de pressão fossem pontos definidos pela sua própria natureza objetiva e que a presença delas significa, invariavelmente, o desencadeamento do estresse. Segundo os Autores na abordagem psicológica, a preocupação centra-se na forma como os indivíduos vão se relacionar e lidar com as fontes de tensão, levando em consideração as vivências e os mecanismos individuais e coletivos para reduzir o sofrimento e o estresse. Nesta abordagem, as fontes de tensão possuem natureza tanto objetiva quanto subjetiva. Os autores afirmam também que na abordagem biológica as fontes de tensão configuram-se como fatos reais e ameaçadores para os indivíduos e que na abordagem psicológica a interpretação dos indivíduos de fatos reais pode criar distorções acerca deles e que as fontes de tensão podem ser criadas, ampliadas, reduzidas ou, até mesmo, ignoradas, como parte do processo de relacionamento e vivência individual com a realidade. Assim, indivíduos expostos às mesmas fontes de tensão não as percebem da mesma maneira e não reagem de forma homogênea diante delas.

Já na abordagem sociológica as fontes de tensão no trabalho vão variar de acordo com as transformações estruturais mais amplas, dependendo dos valores, conceitos e novos elementos presentes no trabalho. Segundo Marras e Veloso (2012) as fontes de pressão podem se configurar, por exemplo, a partir de novas tecnologias que vão alterar a relação do indivíduo com seu trabalho.

O modelo apresentado foi aplicado a esse artigo, uma vez que, possibilita intervenção por meio de diagnóstico, de acordo com Honório (1998), quanto a elementos relacionados à 
tarefa, remuneração, promoção e liderança. E esses possíveis diagnósticos permitem aos gestores, como explica Zille (2005), obter explicações para questões quanto aos efeitos do estresse normalmente experimentados por um indivíduo ou grupo, a forma do comportamento em meio a essas situações e estratégias utilizadas pelo grupo para enfrentar o estresse.

Considera-se que vivemos em realidades construídas socialmente e que, por forças das circunstâncias sociais, nem sempre reagimos às situações estressoras de uma forma conveniente para nosso organismo biológico. Dessa forma, um indivíduo convive, sem lutar ou fugir, por exemplo, com diversos agentes estressores no ambiente ocupacional pela necessidade de trabalhar.

De outro lado, entende-se que o indivíduo pode desenvolver diferentes estratégias para lidar com os agentes estressores que não se configuram diretamente como luta ou fuga em relação às fontes de pressão, mas que procuram minimizar seus impactos, sendo estas denominadas estratégias de enfrentamento (MARRAS; VELOSO, 2012).

O termo utilizado para tratar as estratégias de enfrentamento é coping. Anaut (2005) argumenta que coping significa ações desenvolvidas pelo indivíduo para fins de adaptação e ajustamento a situações difíceis. As estratégias de coping constituem processos que permitem a gestão por parte dos indivíduos de situações de discrepâncias a que estão submetidos e os recursos que possuem diante de situações indutoras de estresse. Por tais estratégias entende-se um esforço cognitivo e comportamental do indivíduo na tentativa de gerenciar tanto o ambiente quanto às demandas internas e aos conflitos que possam estar o afetando.

Ao utilizar estratégias de enfrentamento, o indivíduo está buscando ser proativo, para resolver os obstáculos que circundam a sua vida. Entendidas como processo, as estratégias de enfrentamento podem ser aprendidas, usadas e descartadas, de acordo com a possibilidade de identificação e reforço em dado momento (LAZARUS; FOLKMAN, 1984).

Cooper, Sloan e Willians (1988) sintetizam tais estratégias em quatro tipos de ações adotadas pelo sujeito: gerenciar seu tempo; contar com apoio social (parentes, amigos, profissionais); distrair-se com passatempos; e racionalizar os eventos pelos quais passa, de modo a manter sua integridade psíquica. Considerando que o enfrentamento é uma resposta ao estresse, correspondente aos esforços cognitivos e comportamentais orientados para lidar com as demandas externas e/ou internas que estejam excedendo ou sobrecarregando os recursos do sujeito, fica evidenciado que a maneira como o indivíduo se posiciona diante das situações vivenciadas influenciará a propensão ao estresse. 


\subsection{A função do contador e suas responsabilidades na atualidade}

De acordo com Marion (2003) a função básica do contador é produzir informações úteis aos usuários da contabilidade para auxiliar nas tomadas de decisões.

Silva (2003) em concordância, afirma que o contador é o informante essencial para levar a empresa ao sucesso ou não, uma vez que pode analisar dados passados, perceber presentes e prever eventos futuros.

Lisboa (1997), afirma ainda, que o contador supri com informações desejadas, os diferentes tipos de usuários, de acordo com suas necessidades, não buscando benefícios de qualquer um de forma particular.

Conforme Thomé (2001) a rotina e a demanda dentro de um escritório de contabilidade são muito grandes, o contador tem uma serie de obrigações subdivididas em diversos seguimentos na prestação de serviços entre o cliente e o contador. Além de controlar todo o patrimônio da empresa, o contador tem a função de ainda informar ao seu cliente toda a situação da sua empresa, esse profissional obtém informações não apenas para seus clientes que na maioria das vezes vê o contador como um cobrador de impostos (serve mais ao setor publico do que ao seu cliente), todo o circulo da empresa para qual ele presta serviços. $\mathrm{O}$ autor afirma que dentre as suas funções rotineiras destacamos planilhas documentos, folhas de pagamentos, guias preenchidas pela internet, prazos apertados para a entrega da documentação, cobrança dos contratantes, fechamento de livros para prestação de contas, gera uma tensão muito grande no fechamento de todo o seu trabalho, sem contar a cobrança do cotidiano muita das vezes por causa da tensão e pressão pode ocorrer estresse nesse profissional da área.

Marion (1999) apresenta que a cada dia surgem mais vagas para o profissional, mas que para ser aceito, ele deve acompanhar a evolução da área. Os contadores devem estar sempre atualizados, atentos às mudanças, caso contrário poderá perder seu lugar para outro profissional. Deve também estar sempre conectado com os outros setores da empresa, não se contentando apenas com assuntos fiscais e contábeis afirma o autor. $\mathrm{O}$ contador deve ter ainda conhecimento cultural, se informando sobre tudo que acontece no mundo. Quanto ao seu comportamento ético-profissional, deve tê-lo como inquestionável, participar de eventos específicos da sua área profissional e estar sempre consciente de sua responsabilidade social e profissional. 


\subsubsection{Estresse ocupacional nos contadores}

Pesquisas do Isma Brasil 2014 indicam que 70\% dos profissionais brasileiros sofrem alguma sequela devido ao alto nível de stress. Desse total, 30\% atingiram o nível mais elevado, conhecido como Burnout - esgotamento mental intenso causado por pressões no ambiente profissional.

Visto como um dos males da pós-modernidade, o estresse pode assolar o trabalhador de qualquer área, mas, inegavelmente, aqueles que lidam diretamente com as contas de uma pessoa física ou jurídica e são responsáveis pelos balanços, fechamentos e relatórios tornamse os mais atingidos. Tudo isso combinado com o aumento das obrigações e a obrigatoriedade de adaptação às novas exigências fiscais e ferramentas tecnológicas agrava ainda mais esse "gatilho" para o aparecimento de outras doenças.

A dor de cabeça nas Ciências Contábeis parece não ter fim. Por outro lado, os profissionais de contabilidade nunca foram tão valorizados, inclusive economicamente. Pesquisa realizada pela empresa de recrutamento especializada Robert Half estima que 58\% dos diretores financeiros do Brasil esperam aumento na remuneração dos profissionais de finanças e contabilidade em 2014. Os resultados do estudo, realizado com 2.535 executivos de finanças e contabilidade de 16 nacionalidades, colocam o Brasil como quarto país em que mais se aposta em aumento salarial para esses executivos neste ano, atrás apenas da China (70\%), Hong Kong (69\%) e Nova Zelândia (60\%).

Entre os principais geradores de estresse, segundo levantamento da Isma Brasil, em primeiro lugar está à falta de tempo para realizar um número cada vez maior de tarefas. A sobrecarga de trabalho e o excesso de atividades são apontados por $64 \%$ dos entrevistados como o primeiro dos grandes vilões para o bem-estar.

Após, na lista da entidade, está o medo da demissão, tido como grande fonte de ansiedade para 56\% das pessoas ouvidas. Em terceiro lugar, vem o excesso de responsabilidade e a falta de autonomia, fator destacado por $47 \%$ dos entrevistados e que "assola principalmente os responsáveis pela área financeira e, consequentemente, contábil", enfatiza Ana Maria Rossi, presidente do Isma Brasil e doutora em psicologia clínica.

Além desses três fatores diagnosticados em pesquisa, a psicóloga lembra que o desequilíbrio entre a valorização e o esforço empenhado também é um fenômeno a ser levado em conta ao analisarmos os níveis de estresse no País. "Muitos profissionais sentem que estão 
trabalhando mais do que deveriam por que não são gratificados pela colaboração. E essa gratificação nem precisa ser financeira. Às vezes, um tapinha nas costas é suficiente", pontua.

O presidente do Conselho Regional de Contabilidade (CRCRS), Antônio Palácios, afirma que há certo agravamento do estresse cotidiano exatamente pela necessidade de estar em constante adaptação e pelo grande acúmulo de tarefas e responsabilidades nas mesas dos contadores. "Aumentaram as exigências da Receita Federal, que hoje são o principal motivo de atenção da maioria dos nossos profissionais, e as evoluções tecnológicas ocorrem em uma velocidade que a categoria não consegue acompanhar" (MELLO, 2014)

\section{METODOLOGIA}

De acordo com Rodrigues (2007) metodologia é um conjunto de abordagens, técnicas e processos utilizados pela ciência para formular e resolver problemas de aquisição objetiva do conhecimento, de uma maneira sistemática.

A metodologia que será utilizada na pesquisa do nosso trabalho será detalhada nos subitens: tipo de pesquisa, estudo de caso, unidade de análise, coleta de dados e tratamento de dados.

\subsection{Tipo de pesquisa se abordagem de pesquisa}

O estudo utilizou fins descritivos, porque segundo Gil (2006) tem como objetivo primordial a descrição das características de determinada população ou fenômeno ou o estabelecimento de relações entre as variáveis.

Conforme explica Gil (2006), a pesquisa descritiva busca descrever as características de uma população ou fenômeno.

Segundo Bradley (1993), em pesquisas qualitativas, as grandes massas de dados são quebradas em unidades menores e, em seguida, reagrupadas em categorias que se relacionam entre si deforma a ressaltar padrões, temas e conceitos. Nesse caso o objetivo é identificar os fatores que levam os profissionais que atuam no ramo de contabilidade a se estressar.

\subsection{Unidade de análise}


Esse trabalho tem como os sujeitos de pesquisa os contadores que atuam no ramo de contabilidade a mais de 5 anos, graduados e que atuam em escritórios de contabilidade no município de Belo Horizonte/ MG.

O sujeito de pesquisa segundo Marion (2000) é o profissional encarregado de trabalhar com a área financeira, econômica e patrimonial de uma ou várias pessoas jurídicas. Faz parte das tarefas deste profissional estar totalmente adequado às leis que dizem respeito ao patrimônio das pessoas jurídicas, datas e prazos dos impostos que a empresa deve pagar e interpretar, de forma correta, as informações coletadas para, desta forma, saber que atitudes devem ser tomadas para o crescimento das empresas onde exerce suas funções.

\subsection{Coleta de Dados}

Vergara (2000), fala que a coleta de dados é a forma de como se obtém os dados necessários para responder ao problema de pesquisa. Ele completa dizendo que esse método inclui entrevistas, aplicações de questionários, testes e observações.

Foi feito um roteiro de pesquisa semiestruturado, aplicado aos cinco contadores. Esses dados foram analisados visando identificar as subcategorias que pressionam o trabalho do sujeito de pesquisa. As categorias de pressão de trabalho referem se as categorias descritas por Cooper, Sloan e Willians (1988), sendo elas: fatores intrínsecos ao trabalho, papel gerencial, inter-relacionamento, desenvolvimento na carreira, estrutura e clima organizacional e interface casa e trabalho.

\subsection{Tratamento de dados}

Conforme modelo de Cooper, Sloan e Willians (1988) os fatores de pressão no trabalho são: Fatores Intrínsecos ao Trabalho, Papel Gerencial, Inter- relacionamento, Desenvolvimento na Carreira, Estrutura e Clima Organizacional e Interface Casa Trabalho.

Os dados obtidos foram submetidos à análise de conteúdo proposta por Bardin (1977), técnica que possibilita uma avaliação mais clara dos conteúdos e opiniões das mensagens. O autor afirma que, a análise de conteúdo pode ser definida como o conjunto de técnicas de análise de comunicação visando obter, por procedimentos sistemáticos e objetivos da descrição do conteúdo das mensagens, indicadores que permitam a inferência de 
conhecimentos relativos às condições de produção/recepção destas mensagens. Aspectos esses que se concretizam por meio da definição das categorias de análise.

As entrevistas foram gravadas e, depois transcritas mantendo o conteúdo das mesmas. Fez-se o agrupamento do conteúdo de acordo com as categorias de análise do modelo teórico onde posteriormente, fez-se a atenuação do material, por meio de sumarização, de forma a restarem apenas os conteúdos mais importantes relacionados às categorias (BARDIN, 1977). Dessa forma, emergiram subcategorias, as quais se destacaram, tendo uma frequência superior a dois respondentes e recorrendo-se a critérios de repetição e relevância para interpretação do conteúdo das entrevistas.

\section{Análise dos Dados}

No presente capítulo relata-se análise dos dados obtidos a partir das respostas dos participantes da pesquisa. Serão apresentados fatores relativos à pressão no trabalho no estudo focado nos contadores de Belo Horizonte.

Esta etapa do estudo tratará da análise de dados que partiram da adaptação do modelo de Cooper, Sloan e Williams (1988) para o diagnóstico de estresse ocupacional. O Quadro 1 descreve os dados demográficos e ocupacionais dos entrevistados.

Quadro 1 - Perfil dos entrevistados

\begin{tabular}{|c|c|c|c|c|c|c|c|}
\hline Entrevistado & Sexo & $\begin{array}{c}\text { Estado } \\
\text { civil }\end{array}$ & $\begin{array}{c}\text { Tempo } \\
\text { empresa }\end{array}$ & $\begin{array}{c}\text { Tempo de } \\
\text { profissão }\end{array}$ & $\begin{array}{c}\text { Escolaridad } \\
\text { e }\end{array}$ & Idade & $\begin{array}{c}\text { Horas } \\
\text { semanais } \\
\text { trabalhadas }\end{array}$ \\
\hline E1 & $\mathrm{F}$ & Solteiro & 5 anos & 05 anos & $\begin{array}{c}\text { Superior } \\
\text { comp. }\end{array}$ & $\begin{array}{c}28 \\
\text { anos }\end{array}$ & $44 \mathrm{hs}$ \\
\hline E2 & $\mathrm{F}$ & Solteiro & $\begin{array}{c}1 \text { ano e } 6 \\
\text { meses }\end{array}$ & 06 anos & $\begin{array}{c}\text { Superior } \\
\text { comp. }\end{array}$ & $\begin{array}{c}22 \\
\text { anos }\end{array}$ & $44 \mathrm{hs}$ \\
\hline E3 & $\mathrm{M}$ & Solteiro & 6 anos & 06 anos & $\begin{array}{c}\text { Superior } \\
\text { comp. }\end{array}$ & $\begin{array}{c}27 \\
\text { anos }\end{array}$ & $44 \mathrm{hs}$ \\
\hline E4 & $\mathrm{F}$ & Casado & 5 anos & 10 anos & $\begin{array}{c}\text { Superior } \\
\text { comp. }\end{array}$ & $\begin{array}{c}38 \\
\text { anos }\end{array}$ & $50 \mathrm{hs}$ \\
\hline E5 & $\mathrm{M}$ & $\begin{array}{c}\text { Divorciad } \\
\text { o }\end{array}$ & $\begin{array}{c}2 \text { anos e } \\
\text { meio }\end{array}$ & 10 anos & $\begin{array}{c}\text { Superior } \\
\text { comp. }\end{array}$ & $\begin{array}{c}32 \\
\text { anos }\end{array}$ & $50 \mathrm{hs}$ \\
\hline
\end{tabular}

Fonte: Dados da pesquisa.

Os resultados evidenciam que $60 \%$ são do sexo feminino, $40 \%$ são do sexo masculino, $60 \%$ são solteiros, $20 \%$ casados e $20 \%$ divorciados. A média do tempo de trabalho e de 3 anos e 8 meses, e a media de tempo de profissão é de 7 anos e 4 meses. A faixa etária dos entrevistados gera em torno de 30 anos em média. 100\% dos entrevistados tem ensino 
superior completo, $60 \%$ dos entrevistados trabalham 44 horas semanais e $40 \%$ trabalham 50 horas semanais.

\subsection{Fatores de pressão no trabalho}

Podemos perceber pelo Quadro 2 que a partir das categorias emergiram subcategorias de pressão de trabalho dos entrevistados.

Quadro 2 - Categorias e Subcategorias de pressão no trabalho, sintomas físicos e mentais e estratégia de combate ao estresse.

\begin{tabular}{|l|l|}
\hline \multicolumn{2}{|c|}{ FATORES DE PRESSÃO MODELO DE COOPER, SLOAN E WILLIAMS (1988). } \\
\hline CATERGORIAS & SUBCATEGORIAS \\
\hline Fatores intrínsecos ao trabalho & $\begin{array}{l}\text { Excessivo volume de trabalho } \\
\text { Ritmo acelerado no processamento das informações }\end{array}$ \\
\hline Papel Gerencial & $\begin{array}{l}\text { Excesso de burocracia } \\
\text { Falta de apoio e Orientação } \\
\text { Desconhecimento da filosofia de gestão }\end{array}$ \\
\hline Desenvolvimento na carreira & $\begin{array}{l}\text { Falta de oportunidade de crescimento } \\
\text { Falta de treinamentos }\end{array}$ \\
\hline Estrutura e clima organizacional & Falta de Feedback \\
\hline Interface casa e trabalho & Trabalho excede o horário de jornada \\
\hline Sintomas físicos & $\begin{array}{l}\text { Dores no corpo } \\
\text { Fadiga }\end{array}$ \\
\hline Sintomas mentais & $\begin{array}{l}\text { Desanimo } \\
\text { Desmotivação }\end{array}$ \\
\hline Estratégias de combate ao estresse & $\begin{array}{l}\text { Sair com os amigos } \\
\text { Ouvir musica } \\
\text { Beber cerveja/vinho }\end{array}$ \\
\hline
\end{tabular}

Fonte: Resultados da pesquisa

Quanto aos Fatores Intrínsecos ao trabalho evidenciaram-se as subcategorias excessivo volume de trabalho e de Ritmo acelerado no processamento das informações, os depoimentos dos entrevistados evidenciaram essas situações:

\footnotetext{
"'Atualmente a gente considera a carga de, de execução de trabalho um pouco é corrida, vamos dizer assim corrida, apertada mesmo para, para todas as obrigações rescisórias, para atendimento ao cliente, é para consultoria, é entendimento a legislação, estudo a legislação então hoje, atualmente a gente considera um pouco apertado."'” (E4).

"'Em dias que eu tenho que fazer folha de pagamento o ritmo é muito intenso e como eu estou sozinha eu tenho que estar fazendo tudo em um prazo muito curto."' (E1).
} 
Sobre o papel gerencial também evidenciou-se a subcategoria de excesso de burocracia, falta de apoio e orientação e o desconhecimento da filosofia da organização, que é um fator que gera muita pressão no trabalho, conforme os depoimentos:

\begin{abstract}
"Na verdade eu me considero o departamento fiscal sem qualquer apoio, eu só tenho apoio quando eu chego com um problema, eu não tenho apoio antecedente ao problema, é, é, eu não tenho apoio de sentar e a gente ter uma reunião onde que se discuta é pontos que se pode é pontos chaves com o cliente, pontos chaves de uma futura fiscalização é, é, a gente não tem reuniões, nós não temos, nós só temos reuniões quando surge um problema quando a bomba estoura então eu não tenho apoio nesse sentido.'”' (E4).

"'Eu nunca ouvi falar, de onde eu trabalho dessa eu não sei, não sei se tem filosofia e se tem qual que é."'” (E2).
\end{abstract}

Com respeito ao Inter-relacionamento, todos os entrevistados disseram ter um bom relacionamento entre com seus companheiros e que os conflitos existem, mas não são de grande proporção e são facilmente resolvidos, até por isso os superiores não demonstram interesse em interferir nos eventuais conflitos. Portanto, essa categoria não causa pressão no trabalho dos entrevistados.

Com relação ao desenvolvimento de carreira, os entrevistados disseram que suas empresas não possuem um plano para desenvolvimento da carreira, nem fornece treinamento para os funcionários, logo, eles não têm expectativa para crescimento dentro da organização. Os depoimentos abaixo evidenciam essa situação:

\footnotetext{
"Não tem plano de carreira na empresa, é não tem é promoção, não tem é a gente não recebe participação dos lucros, então isso dificulta muito, muito é, é dentro de uma empresa você manter aquele quadro de funcionários sempre por isso que aqui a rotatividade é enorme."'” (E4).

"'Os treinamentos recebidos eu nunca tive sabe, mas eu acredito também que não tem como ter, por que, até cursos essas coisas assim que a gente procura querer fazer se tiver que usar o horário do serviço à gente não pode."”' (E2)
}

Já sobre Estrutura e clima organizacional, é vista de forma satisfatória, principalmente entre os próprios funcionários, quando tratamos da comunicação entre diretoria/funcionários, os entrevistados ainda assim avaliaram como boa, mas a maioria relatou que a falta de feedback ainda é um problema dentro das organizações.

\begin{abstract}
"'A comunicação eu avalio como péssima, eu acho que falta muito feedback internamente muito, muito, exemplos de, de, nós sabemos de situações de cliente pelo cliente de uma reunião que foi feita com os diretores isso acontece muito então eu acho que a comunicação interna tanto quanto diretores e funcionários, entre funcionários não é boa, o feedback aqui não funciona."” (E4).
\end{abstract}

Quando o tema foi Interface casa trabalho, a maioria dos entrevistados relatou que o trabalho desempenhado por eles muitas vezes precisa exceder o horário de jornada semanal. 
Também frequentemente, nos momentos que deveriam ser de descanso, eles ficam preocupados com situações que ocorrem no trabalho.

“'Já existiu e com certeza vai existir muitos, situações que eu vou ter que abrir mão de um final de semana para trabalhar é de um sábado né, só que é eu tento levar numa boa né, só que às vezes a gente não tem opção."' (E4).

Isso de certa forma interfere diretamente no relacionamento com os familiares. Quando há alguma necessidade de se compartilhar o tempo no serviço com algum imprevisto ou situação que requer uma atenção na vida pessoal, já há um pouco de dificuldade em conciliar.

Em relação aos sintomas físicos, todos os e entrevistados disseram sentir algum tipo de problema físico, na sua maioria dores no corpo e a fadiga, como relatados nos depoimentos:

\footnotetext{
"'Eu sinto muita dor no maxilar, eu percebi que hoje eu tenho bruxismo, por causa do meu estresse, muita dor de cabeça esse tipo de coisa'”'. (E1)

"O que cansa mais é a mente, é o seu raciocínio chega uma hora que realmente parece que por isso que eu acho que existe as né, a gente trabalha 9 horas para compensar o sábado, mas eu acho que existe um limite, por isso que até eu acho que até testaram isso em ser humanos, por que, você não consegue raciocinar mais"'”.(E4).
}

Já quanto a sintomas mentais, foi citado o desânimo, desmotivação dentro e fora da empresa, como foi citada nos depoimentos:

\begin{abstract}
"'Eu acordo de manhã e não tenho vontade de ir trabalha não é um lugar que você se sente se sente bem"'. (E2).

"'Emocionalmente hoje eu me sinto um pouco desmotivada né é com relação a, a, a gestão interna, não é nem com o meu trabalho, por que, eu amo fazer departamento fiscal é, é o que eu gosto sabe, isso não muda eu vou passar de empresa para empresa é, é a rotina vai ser a mesma isso não muda"'.' (E4).
\end{abstract}

A maioria dos entrevistados disse que busca sair com amigos uma forma de se distrair e tentar combater o estresse, ouvir música e o consumo de bebida alcoólica também foi citado como estratégia de combate ao estresse.

"'Eu bebo um vinho de boa qualidade tenho aprendido sobre isso e eu sou rapper de uma banda que não convém dizer"'”. (E5).

\title{
5. CONSIDERAÇÕES FINAIS
}

O objetivo dessa pesquisa foi diagnosticar o nível de estresse ocupacional numa amostra de cinco contadores formados, que atuam em escritórios de contabilidades na cidade 
de Belo Horizonte/MG, e para isso foi utilizado o Modelo Teórico para Explicar o Estresse Ocupacional, desenvolvido por Cooper, Sloan e Williams (1988).

Os resultados mostraram que as fontes de pressão na atividade exercem uma tensão alta sobre os contadores entrevistados. As maiores fontes de pressão são quanto ao avanço tecnológico, que aumentou as responsabilidades dos profissionais, os trabalhos a serem executados, o ritmo acelerado, desconhecimento da filosofia de gestão, pequenas possibilidades de crescimentos, extensa jornada de trabalho e condições e trabalhos inapropriados.

Foi diagnosticado também que as principais características relacionadas ao estado de estresse em contadores são por julgarem o trabalho como estressante, pesado, relatam cansaço após uma jornada de atividade, a vida geralmente é sedentária, a realização de atividades trabalhistas em dias que seriam de folga gerando necessidade de realizar ações no sentido de reduzir estresse.

Outra constatação relevante é o tempo de exercício na função, pois está diretamente relacionado ao nível de estresse ocupacional. Existe uma tendência de aumento no estresse na medida em que os contadores acumulam maior tempo na função contábil em escritórios de contabilidade.

A análise permitiu verificar que grande parte dos entrevistados buscam em atividades com amigos, música e bebida alcoólica, uma forma de se distrair e assim amenizar os efeitos causados pelo estresse.

Como limitação dessa pesquisa apresenta-se o número de entrevistados, fato que não permite a generalização dos resultados obtidos. Todavia, ainda existem poucas análises e pesquisas sobre estresse ocupacional na área contábil, sugerindo-se a realização de novas pesquisas qualitativas em outras regiões da que foi pesquisada neste estudo e a realização de pesquisas quantitativas com o objetivo de triangular os dados encontrados neste estudo.

\section{REFERÊNCIAS}

ANAUT, Marie. A resiliência: ultrapassar os traumatismos. Trad. de Emanuel Pestana. Lisboa: Climepsi Editores, 2005

BARDIN, L. Análise de conteúdo. Tradução de L.A. Reto e A. Pinheiro. Lisboa: Edições70, 1977.

BENEDICTO, S. C. et al. Estresse e Psicopatologias no Ambiente de Trabalho: Conceitos, Contextos, Manifestações e Conseqüências. In: SEMINÁRIOS EM 
ADMINISTRAÇÃO FEA USP, 2006, São Paulo. Anais eletrônicos. Disponível em: <http://www.ead.fea.usp.br/semead/9semead/resultado_semead/trabalhosPDF/5.pdf >. Acesso em: 09 jul. 2012.

BRADLEY, Jana. Methodological issues and practices in qualitative research. Library Quarterly, v. 63, n. 4, p. 431-449, Oct. 1993.

BRASIL. Lei $\mathrm{n}^{\circ}$ 6.404, de 15 de dezembro de 1976. Dispõe sobre as sociedades por ações. Publicado em 17 de dezembro de 1976. Disponível em:

<http://www.planalto.gov.br/ccivil_03/Leis/L6404consol.htm>. Acesso em 25 de out 2014.

Cooper, C. L., Sloan, S., \& William, S. (1988) Occupational stress Indicator managementvguide. London: Windsor.

FRANÇA, A.C.L \& Rodrigues, A.L. Stress e Trabalho. Uma abordagem psicossomática. 2.ed. São Paulo: Atlas, 1999.

FRASER TM. Human stress, work and job satisfaction: a critical approach. Germany: International Labour Office; 1983.

GIL, A.C. Métodos e técnicas de pesquisa social. 5. ed. São Paulo: Atlas, 2006.

GOLDBERG, P. A saúde dos executivos: como identificar sinais de perigo para a saúde e levar a melhor contra o estresse. Rio de Janeiro: Guanabara, 1986.

GOLDBERG, Phillip. A saúde dos executivos: como identificar sinais de perigo para a saúde e levar a melhor contra o estresse. Rio de Janeiro: Zahar, 1980.

HONÓRIO, Luiz Carlos. Cisão e Privatização: impactos sobre a qualidade de e vida no trabalho de uma empresa de telefonia celular. 1998. f. Dissertação (Mestrado em Administração) - CEPEAD, Universidade Federal de Minas Gerais, Belo Horizonte.1998.

HUMPHREY, J.H.; HUMPHREY, J.N. Coping with stress in teaching. New York: AMS Press, 1986.

ISMA BRASIL- Trabalho, Stress e Saúde: a resiliência como estímulo no trabalho - da teoria à ação http://www.ismabrasil.com.br/congressos/congresso-2014/trabalho acesso em 15 de Out. 2014

Lazarus, R. S., \& Folkman, S. Stress, appraisal, and coping. New York: Ed. Springer, 1983.

LIPP, M. E. N. O Stress no Brasil: pesquisas avançadas. Campinas: Papirus, 2004.

LISBOA, L. P. Ética geral e profissional em contabilidade. Fundação Instituto de Pesquisas Contábeis, Atuariais e Financeiras. 2. ed. São Paulo: Atlas, 1997.

MARION, José Carlos. Contabilidade básica. 6. ed. São Paulo: Atlas, 1998. 
MARION, José Carlos; MARION, Márcia Maria Costa. O ensino da contabilidade no Brasil. São Paulo: Atlas, 1999.

MARION, José Carlos; MARION, Márcia Maria Costa. O ensino da contabilidade no Brasil. São Paulo: Atlas, 2000.

MARRAS, Jean Pierre; VELOSO, Henrique Maia. Estresse Ocupacional. Rio de Janeiro: Elsevier, 2012

MELLO Roberta. Jornal do comércio. Contadores à beira de um ataque de nervos. Publicado em 04/06/2014 Disponível em:

http://jcrs.uol.com.br/site/noticia.php?codn=163542. Acesso em 25 de out 2014.

MOLINA, Omar Franklin. Estresse no Cotidiano. São Paulo: Pancast 1996.

RODRIGUES, Willian Costa. Metodologia Científica. 2007. Disponível

em: http://www.ebras.bio.br/autor/aulas/metodologia_cientifica.pdf. Acessado em: 05 out. 2014.

ROSCH, Paul J. In: LIPP, Marilda (org.). Pesquisas sobre estresse no Brasil: saúde, ocupações e grupos de risco. 2. Ed. Campinas: Papirus, 2001.

SELYE, H. The stress of life. Toronto: McGraw-Hill, 1956.

SILVA, Antônio Carlos Ribeiro da. Metodologia da pesquisa aplicada à contabilidade: orientações de estudos, projetos, relatórios, monografias, dissertações, teses. São Paulo: Atlas, 2003.

TAMAYO, Á. Estresse e cultura organizacional. São Paulo: All Books, 2008.

THOMÉ, Irineu. Empresas de Serviços Contábeis: Estrutura e Funcionamento. São Paulo. Editora Atlas 2001.

VERGARA, S. C. Projetos e relatórios de pesquisa em administração. 3. ed. São Paulo: Atlas, 2000.

ZANELLI, J. C. Estresse nas organizações de trabalho: compreensão e intervenção baseadas em evidências. Porto Alegre: Artmed, 2010.

ZILLE, L. P. Novas perspectivas para a abordagem do estresse ocupacional em gerentes: estudo em organizações brasileiras em setores diversos. CEPEAD/UFMG (Tese de doutorado), 2005. 